\title{
Mating strategies in two species of dart-poison frogs: a comparative study
}

\author{
KYLE SUMMERS* \\ Museum of Zoology, University of Michigan, Ann Arbor, MI 48109, U.S.A. \\ (Received 7 February 1991; initial acceptance 13 March 1991; \\ final acceptance 9 October 1991; MS. number: A5969)
}

\begin{abstract}
Comparative field studies of species of dart-poison frogs in the genus Dendrobates were carried out to test predictions from two hypotheses that attempt to explain female-female competition for mates in species of Dendrobates with male parental care. The sex role reversal hypothesis proposes that males invest so much time and energy in parental care that receptive males are rare relative to receptive females, and females compete to find and mate with receptive males. The parental quality hypothesis proposes that females compete to monopolize the parental effort of particular males, because they potentially suffer a cost when their mates care for the offspring of other females. Comparisons between species with male parental care (Dendrobates leucomelas) and female parental care (Dendrobates histrionicus) contradicted prediction of the sex role reversal hypothesis, but were consistent with predictions of the parental quality hypothesis. Male $D$. histrionicus did not compete for mates more aggressively than male $D$. leucomelas, and male $D$. leucomelas were not more selective about mating than male $D$. histrionicus. Female $D$. leucomelas and $D$. histrionicus were both selective about mating; female $D$. leucomelas associated with and competed for particular males, whereas female $D$. histrionicus did not.
\end{abstract}

Dart-poison frogs of the genus Dendrobates (Dendrobatidae) are found in tropical forests of South and Central America (Silverstone 1975). These frogs are terrestrial and diurnal; all known species are aposematically coloured and produce highly toxic alkaloids in skin glands (Myers \& Daly 1983). All species studied so far display parental care in which one parent carries the tadpoles from an oviposition site in the leaf litter to pools of water (Wells 1981; Zimmermann \& Zimmermann 1981; Weygoldt 1987). In some species this behaviour is performed by the male, in others by the female (Silverstone 1975; Zimmermann \& Zimmermann 1988).

Unlike most species of frogs, which mate in or near aquatic habitats (Salthe \& Mecham 1974), dendrobatids court and mate away from water (Wells 1977). Complex and elaborate courtship behaviour has been recorded for many species of Dendrobates, including tactile interactions, long sequences of leading (usually by the male), and following associated with exploration of the leaf litter for oviposition sites, and specific postural displays and call types (Silverstone 1973; Wells 1977).

Physical aggression and agonistic calling and display behaviour have been observed in many

*Present address: Smithsonian Tropical Research Institute, P.O. Box 2072, Balboa, Republic of Panama. species of Dendrobates (Senfft 1936; Crump 1972; Zimmermann \& Zimmermann 1980). In most of these species, male aggression appears to be associated with territory defence (Bunnell 1973; McVey et al. 1981; Zimmermann \& Zimmermann 1981).

In this paper I compare the results of field investigations of two species of dart-poison frogs, one with male, the other with female parental care. In captivity, Dendrobates leucomelas males attend their eggs periodically while the eggs are in the leaf litter developing into tadpoles. This care involves sitting on the eggs, moving them around with their hind legs and shedding water on them. When the eggs have developed into tadpoles, the male allows them to wriggle onto his back (usually one at a time); he then carries them to small pools of water (Zimmermann \& Zimmermann 1980). Dendrobates histrionicus females perform similar care in captivity, except that the tadpoles are placed in smaller pools (e.g. leaf axils of bromeliads) and females return periodically (about once per week for 2 months) to each axil in which they have placed a tadpole and deposit infertile eggs for the tadpoles to feed on (Weygoldt 1980; Zimmermann \& Zimmermann 1981, 1982). Hence, there is a considerable difference between the two species in the role of the sexes in parental care. 
Dendrobates leucomelas has not been previously studied in the field. Zimmermann \& Zimmermann (1980) observed captive animals in terraria. They reported that males did not appear to be aggressive or territorial, but that females were aggressive and developed a hierarchical rank order if kept together in a terrarium. They observed courtship behaviour, in which the female followed and stroked the male as he searched for an oviposition site.

Silverstone (1973) studied $D$. histrionicus at a fieldsite in the Choco region of Colombia. Mark and recapture studies and observations of malemale aggression suggested that males were territorial. Observations on male-female interactions indicated that males and females engaged in both tactile interactions and coordinated movement patterns during courtship. Male territoriality and complex courtship behaviour has also been observed in captive D. histrionicus (Zimmermann \& Zimmermann 1981, 1982).

Dendrobates leucomelas males produce a trill lasting from a few seconds to several minutes (Zimmermann \& Zimmermann 1988). The trill apparently functions both as an advertisement call (i.e. a general purpose call to attract females and warn other males, Wells 1977) and as a courtship call (Zimmermann \& Zimmermann 1980). Calls heard during $D$. leucomelas courtships in the field appeared to be softer and shorter than calls made in other contexts (personal observations), but this has not been verified with recordings. Dendrobates histrionicus males produce three types of calls; an advertisement call, a courtship call, and a release call (Zimmermann \& Zimmermann 1981, 1982). The advertisement call is a series of chirps, repeated so rapidly that they blur together to the human ear (Silverstone 1973; Myers \& Daly 1976). It lasts from several seconds to almost $5 \mathrm{~min}$. The courtship call is a softer, shorter series of chirps, and the release call is a short chirp given when a male is clasped or otherwise disturbed (Zimmermann \& Zimmermann 1981, 1982).

The purpose of comparing these species is to test predictions from two hypotheses that could explain the evolution of female-female competition over mates in species of Dendrobates with male parental care. The sex role reversal hypothesis (Trivers 1972) proposes that females compete for males because males invest more time and energy in each offspring, resulting in a shortage of receptive males (Williams 1966; Trivers 1972; Wells 1981). This hypothesis appears to explain the occurrence of female competition for mates and the high degree of male selectivity for mates observed in species from a variety of taxa. These include pipefishes (Nerophis ophidion; Berglund et al. 1986a, b; Rosenqvist 1990), jacanas (Jacana spinosa; Jenni \& Collier 1972), sandpipers (Actittis macularia; Oring \& Maxson 1978), katydids (Anabrus simplex; Gwynne 1981), and water bugs (Abedus herberti; Smith 1979).

The parental quality hypothesis (Summers 1989) has been described in varying amounts of detail by several authors (e.g. Wittenberger 1979; Blaffer Hrdy \& Williams 1983). It proposes that females will compete for mates if they potentially suffer a cost when their mate also mates with other females. One such cost might be a reduction in the quality or quantity of parental care.

These two hypotheses make different predictions concerning differences between males and females in species with male parental care, and about differences between species with male and female parental care. Previous research tested the predictions of the two hypotheses concerning differences between males and females in D. auratus, a species with male parental care (Summers 1989, 1990a, b). In this paper I present tests of predictions concerning differences between males and females in $D$. leucomelas (with male parental care), and between $D$. leucomelas and D. histrionicus (with female parental care).

The sex role reversal hypothesis predicts the following. (1) In D. leucomelas, female competition for mates will be more frequent and intense than male competition for mates, because receptive males will be rare relative to receptive females. (2) Male $D$. leucomelas will be more selective than females about mating because males invest more per mating, and hence stand to suffer a higher cost from choosing a low quality mate, or from mating at a time or place that will reduce offspring survival. (3) Dendrobates histrionicus males will compete for mates more intensely than $D$. leucomelas males, because the reproductive success of male $D$. leucomelas is not limited by access to females, as it is in D. histrionicus. (4) Dendrobates leucomelas males will be more selective than $D$. histrionicus males, because the number of females they will mate with is constrained by the demands of parental care. (5) Dendrobates leucomelas females will attempt to compete for many different males, because their reproductive success is limited by their ability to 
find receptive males; $D$. histrionicus females will not compete for mates, because their reproductive success is limited by the demands of egg production and maternal care. (6) Dendrobates histrionicus females will be more selective about mating than D. leucomelas females, because they typically invest more per mating.

The parental quality hypothesis predicts the following. (1) Female D. leucomelas will compete for mates, but competition for mates among females will not be more intense than competition among males, because males will compete for access to receptive females. (2) Dendrobates leucomelas females will be more selective about mating than males, because the amount of parental investment that males provide to their offspring is more variable. (3) Dendrobates leucomelas males will compete for females as intensely as $D$. histrionicus males, because their reproductive success increases with the number of females that they mate with. (4) Dendrobates leucomelas and $D$. histrionicus males will both be relatively non-selective about mating (i.e. willing to mate with any female at any time), because males in both species can increase their reproductive success by mating with many females.

(5) Dendrobates leucomelas females will guard particular males to prevent them from mating with other females and caring for their offspring. Dendrobates histrionicus females will not guard their mates, because male polygyny does not impose a cost on the fitness of their offspring. (6) Both D. leucomelas and D. histrionicus females will be selective about mating. Dendrobates leucomelas females will be selective because the amount of parental care provided by males varies depending on the number of clutches their mate is caring for. Dendrobates histrionicus females will be selective because they invest more per mating than males, and hence will suffer a high cost from mating with a low quality male, or from mating at a time or place that reduces offspring growth or survivorship.

\section{METHODS}

The research on D. leucomelas was carried out in tropical dry forest at Maria Luisa, a stream near the Guri hydroelectric dam in central Venezuela. I made observations on 4 days in May, 28 days in June, 11 days in July and 8 days in August, 1987, for a total of 242 study hours. The study area was a shallow slope at the base of a mountain, bordering the stream. A rectangular area $(44 \times 28 \mathrm{~m})$ next to the stream was marked with red flags at $4-\mathrm{m}$ intervals, to facilitate mapping of individual positions. When observing a frog, I would visualize an imaginary 16-block grid within the $16-\mathrm{m}^{2}$ block formed by the flags, and record the $1-\mathrm{m}^{2}$ block (within the 16- $\mathrm{m}^{2}$ block) in which the frog was seen. This allowed me to plot the location of each observation of each frog with reasonable precision. All individuals seen in this plot were caught, measured (snout-vent length), and marked by toe clipping. The colour pattern on the dorsum of each individual was drawn on an identification card to allow recognition of the individual from a distance. These colour patterns were highly variable between individuals, yet highly distinctive, allowing each individual to be recognized easily. Because of low population density, I also marked individuals on a 400-m circular transect in the same area to increase the number of individuals available for behavioural sampling. All frogs caught along this transect were marked and measured in the same way as those caught on the plot.

Dendrobates histrionicus was studied near a small stream, approximately $5 \mathrm{~km}$ east of the coastal town of San Lorenzo, on the northwest coast of Ecuador. I made observations on 12 days in February, 18 days in March, and 8 days in April, for a total of 236 study hours. A rectangular grid $(60 \times 54 \mathrm{~m})$ was constructed, with flags placed at $2-\mathrm{m}$ intervals. Data on the location of frogs were recorded using methods identified above except that the size of the blocks formed by the flags were $4 \mathrm{~m}^{2}$, rather than $16 \mathrm{~m}^{2}$, so that the locations of individuals were recorded as $0 \cdot 5-\mathrm{m}^{2}$ blocks. The studies of both species took place during the rainy season.

Identification of individual $D$. histrionicus using natural markings was not possible, so each frog was given two types of identification mark. I tied a unique combination of coloured beads around the waist of each frog when it was first captured, using cotton thread soaked in paraffin or waxed dental floss. This allowed identification of each individual from a distance, without the need to recapture the individual. Each frog was also toe-clipped in a unique pattern to allow identification in case the identifying beads were lost. Each frog was weighed and measured as described above.

The sex of individual $D$. leucomelas was assessed by examining size, shape and toepad width. Females are larger, have larger, more rounded 
abdomens, and narrower toepads than males (Silverstone 1975, personal observations). The sex of individual $D$. histrionicus was assessed by either playing calls at them, or by putting them in plastic bags and shaking the bags (this treatment typically causes males to respond with a release call, Silverstone 1973). Individuals that did not respond to one of these treatments by calling were assumed to be females. Silverstone (1973) used this technique successfully with this species in Colombia (confirmed by dissection).

I made observations by patrolling the study areas and recording when and where individual frogs were sighted, along with a description of their behaviour. During patrols of the study areas, I attempted to identify (or capture and mark if unmarked) each individual sighted. I recorded calls from individuals in the field using an AudioTechnica microphone (model AT9400) and a General Electric tape recorder (model 3-5016D). I played calls at the areas occupied by marked males (from the edge of the area), and recorded the presence or absence of a response (calling back and/ or moving toward calls). I played calls at the frogs with a General Electric model 3-5016D, or model 3-5300B tape recorder. I placed the volume setting at the highest level with the smaller model (model 3-5300B), and at three quarters of full volume for the larger model, which yielded sound levels that sounded equivalent to me. I was unable to control the precise distance from the frog at which calls were played, because I did not always know where the frog was at the start of the playback. However, for all cases in which frogs did not respond when calls were played at them, the frogs were observed to be within the maximum distance at which they had responded on other occasions. Hence, it is unlikely that lack of response when the frog was present was a result of inability to perceive the stimulus.

If two or more individuals were observed interacting, then the patrol was interrupted and I recorded the sequence of behaviour performed by each individual until the end of the interaction.

I considered as residents all males that were present for at least 2 weeks, and seen in the same area on at least 5 separate days. Males that did not meet these criteria were assumed to be transients. When comparing the relative aggression of males of the two species, it is preferable that the population densities of resident males be similar. Population density was estimated by the cumulative number of residents in an area divided by the total area of the study plot. Both study sites had male population densities of slightly less than one resident male per $100-\mathrm{m}^{2}$ (D. leucomelas: 0.7 males $/ 100-\mathrm{m}^{2} ; D$. histrionicus: 0.9 males $/ 100-\mathrm{m}^{2}$ ). Only residents were used in the analysis of calling behaviour.

Calls were played at the areas where resident males had been captured previously to determine how responsive they were to intrusions by other males. I sampled different males on different days, and varied the number of times that each male was sampled from day to day. I did this because males were first captured on different dates, and some individuals were seen in their areas more frequently, or on different days or times than others. Also, patrols of the study site were occasionally interrupted to follow courtships, so males were not sampled an equal number of times on those days. Because of equipment failure and observer error, calls were not played at each male's area every time that area was visually scanned. Hence, the word 'trial' will be used to denote only instances when the area was visually scanned and calls were played, whereas the word 'sample' will be used to refer to all cases in which a male's area was visually scanned, whether calls were played or not. Any male that did not have calls played at his area at least 10 times was not included in the analysis.

The home ranges, inter-individual distances and the degree of overlap between the home ranges of individuals were calculated with the Newcart mapping program, written by Daniel Fox for the Michigan Interactive Data Analysis System (no documentation available). Home ranges were calculated as minimum convex polygons that included $90 \%$ of the locations where each individual was seen during the study. The grid on the study plot at Maria Luisa in Venezuela (for D. leucomelas) was not completed until near the end of the study, so the average number of days during which the location of a male was recorded for $D$. leucomelas males was small ( $\bar{X}=8$ days $)$.

The criteria used to classify the terminations of female-male encounters were as follows. A female was considered to have rejected a male if she courted with him and then moved away or did not respond when he called, followed or stroked her. A female was considered to have ignored a male if she moved away or did not respond when he approached, called to her, followed her or stroked her. The reciprocal occurrences were taken as evidence for a male rejecting or ignoring a female, 
Table I. The average number of days between the first and last capture or sighting of marked individuals recaptured or resighted at least once (Interval), and the average number of days those individuals were seen, for both species

\begin{tabular}{|c|c|c|c|c|}
\hline & \multicolumn{2}{|c|}{ D. histrionicus } & \multicolumn{2}{|c|}{ D. leucomelas } \\
\hline & Male & Female & Male & Female \\
\hline \multicolumn{5}{|c|}{ Interval } \\
\hline$N$ & 53 & 21 & 29 & 23 \\
\hline $\bar{X}$ & 37.02 & $28 \cdot 38$ & $35 \cdot 41$ & 34.62 \\
\hline $\mathrm{SE}$ & $2 \cdot 14$ & $3 \cdot 14$ & $4 \cdot 24$ & 6.92 \\
\hline \multicolumn{5}{|c|}{ Days sighted } \\
\hline$N$ & 53 & 23 & 29 & 13 \\
\hline $\bar{X}$ & $7 \cdot 66(20 \%)$ & $2.65(7 \%)$ & $7.21(15 \%)$ & $4.39(9 \%)$ \\
\hline SE & 0.86 & $0 \cdot 27$ & 0.81 & 0.57 \\
\hline
\end{tabular}

respectively. Cases in which a female approaching or courting a male was driven away by another female were classified as 'female chases'. Instances in which the male and female separated without clear rejection by either party were classified in the 'separate' category.

The categories used to described female-male associations were as follows. The female number category refers to the identification numbers of the individuals. The observations category shows the ratio of the number of times a females was seen with the male to the total number of times she was seen. Time span refers to the amount of time between the first and last sighting of the pair together. The interactions category lists the results of focal observations on the pairs each time they were seen. The aggression category notes whether the female was seen competing for the male in any of the interactions.

Statistical analyses were performed using SYSTAT (Wilkinson 1987).

\section{RESULTS}

\section{Territoriality}

Forty-five male and 23 female $D$. leucomelas were captured and marked in Venezuela. Sixty-nine male and 60 female $D$. histrionicus were captured and marked in Ecuador. The number of days between the first and last capture of males was longer than that of females in $D$. histrionicus (Table I, Fig. 1; Mann-Whitney $U$-test, $N=127, U=1010$, $P<0.001$ ), but not in $D$. leucomelas (Table $I$, Fig. 1; Mann-Whitney $U$-test, $N=68, U=473$,
$P=0.553$ ). Males were recaptured more frequently than females in $D$. histrionicus (Table I, Fig. 2; Mann-Whitney $U$-test, $N=129, U=859$, $P<0 \cdot 001$ ), but not in D. leucomelas (Table I, Fig. 2; Mann-Whitney $U$-test, $N=68, U=400, P=$ $0 \cdot 118)$. Resident males from both species were seen repeatedly near the area where they were first captured; there was no significant difference between the species in the percentage of samples that resident males were observed in their areas (D. leucomelas: $N=17, \quad \bar{X} \pm \mathrm{SE}=9.7 \pm 0.94$ days out of $43 ; D$. histrionicus: $N=29, \bar{X} \pm \mathrm{SE}=11 \cdot 3 \pm 1 \cdot 2$ days out of 38; Mann-Whitney $U$-test, $U=315, P=0.073$ ). The period between a resident male's first capture and last recapture averaged $46 \cdot 7 \pm 9 \cdot 7$ days for $D$. leucomelas males and $45 \cdot 9 \pm 2 \cdot 2$ days for $D$. histrionicus males; this difference was not significant (Mann-Whitney $U$-test, $N=45, U=250$, $P=0 \cdot 788)$.

Home range sizes calculated for $D$. histrionicus averaged $3 \cdot 9 \pm 0 \cdot 5 \mathrm{~m}^{2}$ for all resident males $(N=29$. range $=0-9 \cdot 2 ;$ Fig. 3), and $5 \cdot 1 \pm 0 \cdot 6 \mathrm{~m}^{2}$ for males whose locations were recorded on at least 10 different days during the study $(N=11$, range $=2$ $8 \cdot 1$ ). Home range sizes averaged $19 \cdot 9 \pm 8 \cdot 1 \mathrm{~m}^{2}$ for resident $D$. leucomelas males $(N=9$, range $=2-81$; Fig. 3), and $38.7 \mathrm{~m}^{2}$ for males whose locations were recorded on at least ten different days $(N=3$. range $=6-81$ ). The home ranges of $D$. leucomelas males were significantly larger than those of $D$. histrionicus males (Mann-Whitney $U$-test, $N=38$, $U=37, P=0.001$ ).

Resident males of both species usually responded aggressively when calls were played at them, by either calling at the recorder, moving towards it, or 


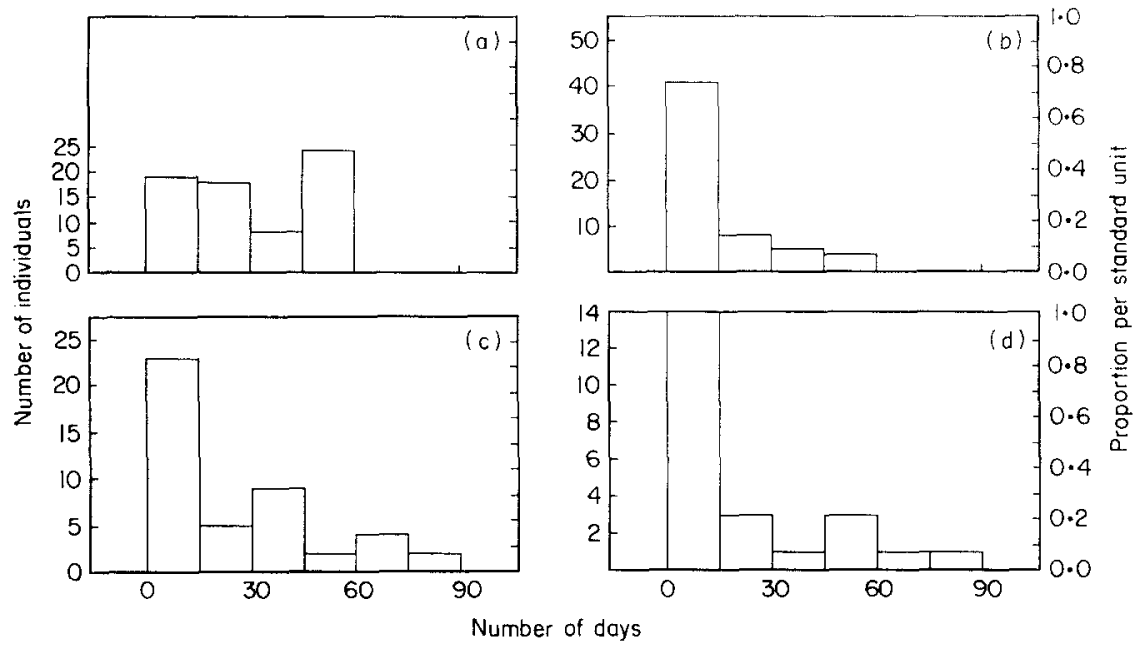

Figure 1. The distribution of the number of days between the first and last sighting of all marked individuals. Proportion per standard unit is the proportion of cases in a bar divided by the standard deviation of the sample as a proportion of the mean. This facilitates comparisons between histograms that utilize different scales. (a) $D$. histrionicus males; (b) $D$. histrionicus females; (c) D. leucomelas males; (d) D. leucomelas females.

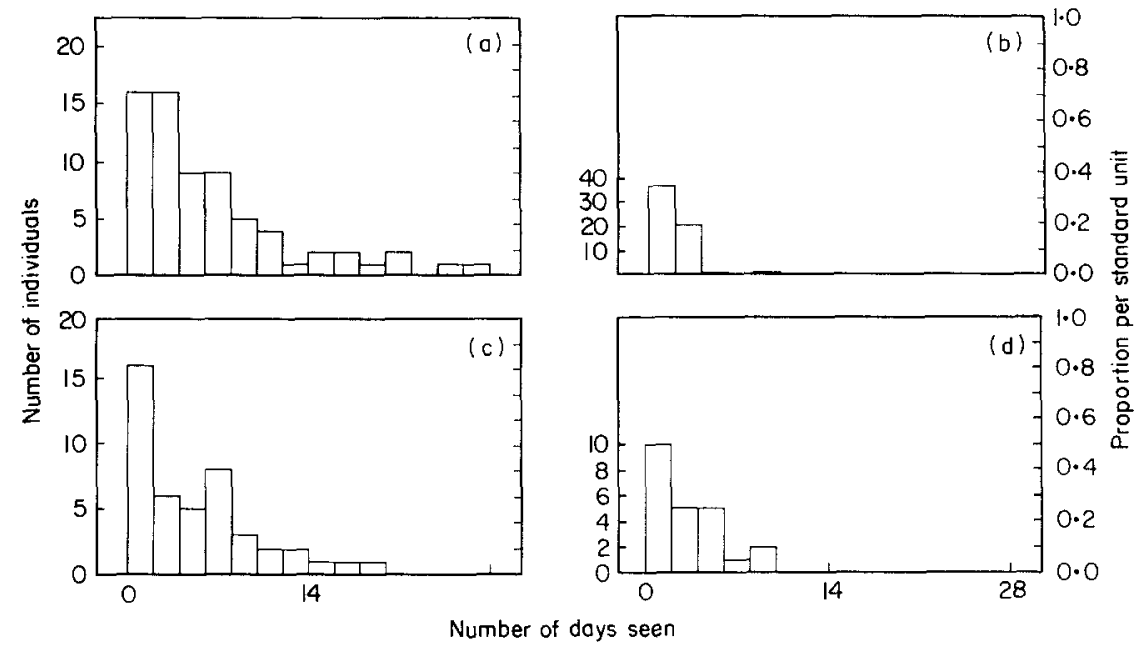

Figure 2. The distribution of the number of days during which marked individuals were seen, for males and females of both species. (a) D. histrionicus males; (b) D. histrionicus females; (c) D. leucomelas males; (d) D. leucomelas females.

both. Males of both species were seen fighting with other males (D. leucomelas: $N=11, D$. histrionicus: $N=2$ ), and also engaged in calling bouts, in which two males faced each other several metres apart and called back and forth for periods ranging from several minutes to over an hour. These observations suggest that resident males of both species are territorial.

\section{Male-Male Competition}

To assess whether $D$. histrionicus males compete for females more intensely than $D$. leucomelas males, I investigated two aspects of calling behaviour and the frequency of physical aggression.

(1) One way of competing for females may be to spend more time calling to attract them. I recorded 


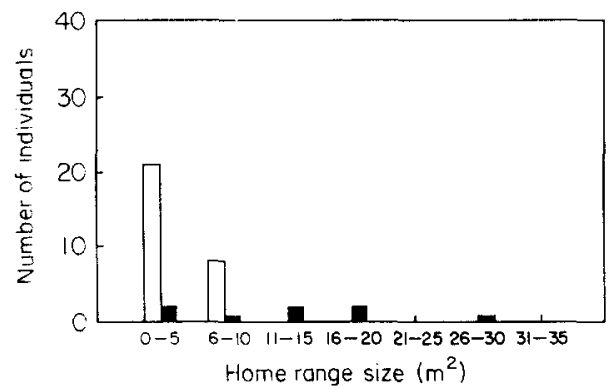

Figure 3. The distribution of home range sizes of $D$. histrionicus ( $\square$ ) and $D$. leucomelas (D) males. One $D$. leucomelas male was not included because of problems of scale; his home range was $81 \mathrm{~m}^{2}$.

whether a male was calling from his territory when I approached it, before calls were played, as a measure of the time males spent advertising their territories. I calculated the number of samples in which a male was found calling in his territory divided by the total number of samples in which the male was seen in his territory. This was used as an estimate of the probability that a male would be calling to attract females when he was in his territory, and compared between species. There was no significant difference between the two species in the percentage of samples in which the male was calling when he was seen in his area (Fig. $4 ; D$. leucomelas: $N=17, \bar{X} \pm \mathrm{SE}=27 \pm 5 \%$, D. histrionicus: $N=29$, $\bar{X} \pm$ SE $=22 \pm 4 \%$; Mann-Whitney $U$-test, $U=197$, $P=0.329$ ).

(2) The percentage of trials in which a male responded to calls when he was seen in his area was taken as a measure of a male's willingness to defend his territory against intruders, which in turn should correlate with the intensity of competition over mates. Dendrobates leucomelas males were significantly more likely to respond to the recorder when they were known to be present than $D$. histrionicus males (Fig. 5 ; D. leucomelas: $N=17, \bar{X} \pm \mathrm{SE}=$ $94 \pm 2 \% ; D$. histrionicus: $N=29, \bar{X} \pm \mathrm{SE}=82 \pm 3 \%$; Mann-Whitney $U$-test, $U=350, P=0.007$ ). This result is unlikely to be due to differences in the playback conditions, because playback sound intensities and distances from the frog were similar, and frogs that did not respond were within the maximum response distance for both species. If male $D$. leucomelas were less likely to be seen when not responding to calls, then this could have biased the results in favour of higher response rates by $D$. leucomelas males. This should have caused the total percentage of response to calls (over all trials) to be

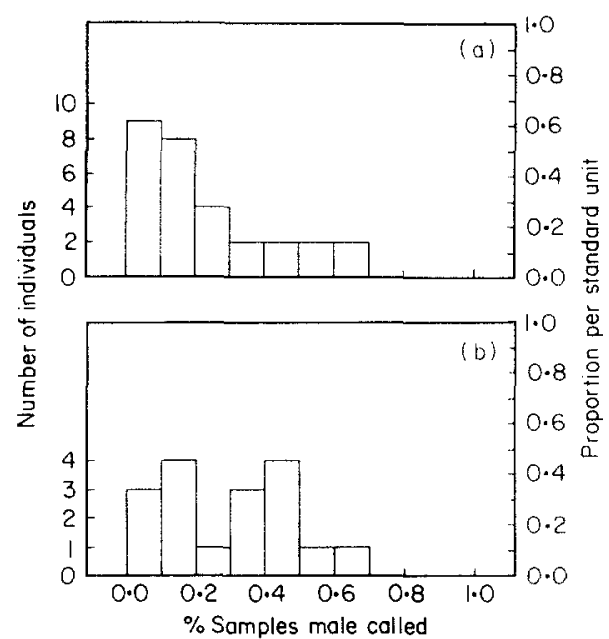

Figure 4. The distribution of the percentage of samples in which males were calling when seen in their areas. (a) $D$. histrionicus males; (b) D. leucomelas males.

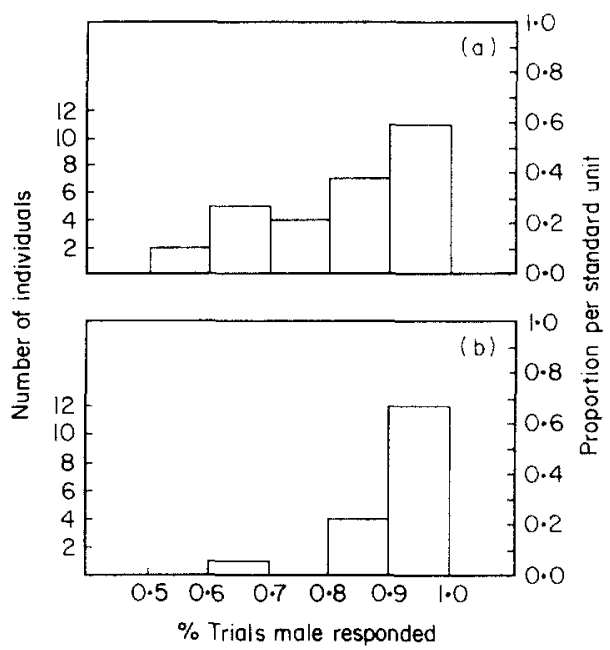

Figure 5. The distribution of the percentage of trials in which males responded, when seen in their areas. (a) $D$. histrionicus males; (b) D. leucomelas males.

lower for D. leucomelas males. I calculated the total number of times each male responded to calls, for all trials between the first and last time the male was sighted in his area. There was no significant difference between $D$. leucomelas and $D$. histrionicus in the percentage of all trials during which males responded to calls (Fig. 6; D. leucomelas: $N=17, \bar{X} \pm \mathrm{SE}=41 \pm 5 \%$; 


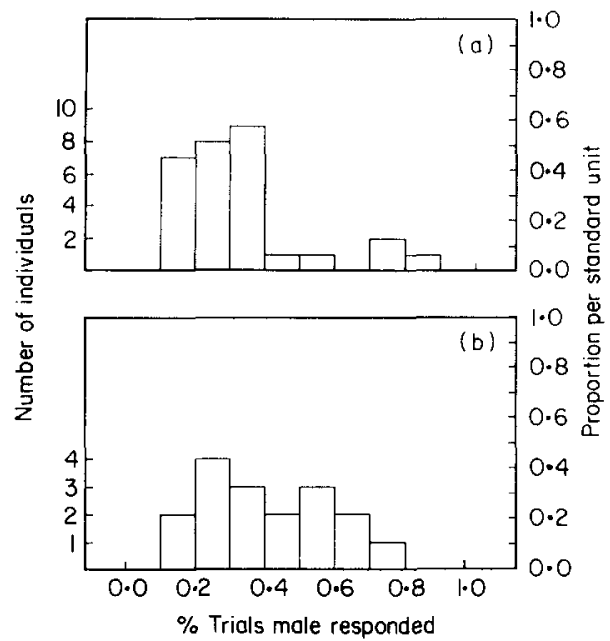

Figure 6. The distribution of the percentage of trials in which males responded to calls played in their areas, for all trials. (a) D. histrionicus males; (b) D. leucomelas males.

D. histrionicus: $N=29, \bar{X} \pm \mathrm{SE}=33 \pm 4 \%$; MannWhitney $U$-test, $U=197, P=0 \cdot 104$ ).

(3) Males of both species fought with other males during this study. The males approached each other, stopping frequently to call back and forth. When they were near each other, one male might jump on the other and attempt to get on its back and clasp it just under the forelegs. If this occurred, the clasping male would then attempt to push his opponent away from his area, or to press him to the ground. The other male resisted by locking his forelegs straight out and blocking his opponent's attempts to push him, or by attempting to throw the male off his back. Males also grappled face to face, and whirled in a circle, each one apparently trying to get on the other's back. The number of bouts of physical aggression between males was taken as an indicator of the intensity of male-male competition for mates. The frequency of aggression was measured as the number of bouts per day. There were more samples per day for D. histrionicus (a greater number of resident males and observers), which could bias the results towards a higher frequency of fights in $D$. histrionicus. There were significantly more fights per day between $D$. leucomelas males than between $D$. histrionicus males (D. Leucomelas: $N=46, \bar{X} \pm \mathrm{SE}=0 \cdot 26 \pm 0.07$ fights per day; $D$. Histrionicus: $N=38, \bar{X} \pm \mathrm{SE}=$ $0.05 \pm 0.04$ fights per day; Mann-Whitney $U$-test, $U=710, P=0.019$ ).

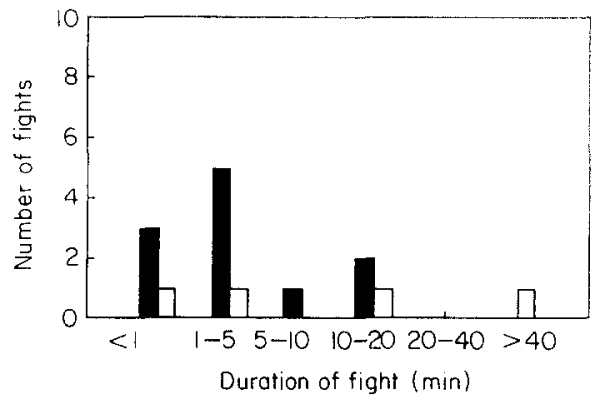

Figure 7. The distribution of aggressive interaction durations for male ( $\square$ ) and female $(\square) D$. leucomelas (does not include calling bouts between males).

\section{Female Aggression}

Female $D$. leucomelas were observed engaging in intrasexual aggression four times during the study. Female-female aggression always occurred in the presence of a calling male, and both females repeatedly attempted to approach the male during the fight. There were more male-male fights per day than female-female fights (Fig. 7; males: $\bar{X} \pm \mathrm{SE}=0.26 \pm 0.07$ fights per day; females: $\bar{X} \pm \mathrm{SE}=0.087 \pm 0.04$ fights per day; MannWhitney $U$-test, $N=46, U=895, P=0.047$ ). There was no significant difference between male and female fight durations in D. leucomelas (Fig. 7; males: $\bar{X} \pm \mathrm{SE}=4.73 \pm 1.98 \mathrm{~min}$; females: $\bar{X} \pm \mathrm{SE}=$ $15.83 \pm 11.29 \mathrm{~min}$; Mann-Whitney $U$-test, $N=15$, $U=28, P=0.468$ ).

\section{Courtship}

Courtship leading to oviposition was observed nine times in both $D$. leucomelas and $D$. histrionicus. Courtship behaviour in $D$. leucomelas typically involved prolonged exploration of the leaf litter, with the male leading. The female frequently stroked, nudged and climbed on the male as she was following him. The male called at the female intermittently during the courtship. Males appeared to call more frequently when they became separated from the female, or when they were out of the female's sight (e.g. under the leaf litter). Oviposition was not observed in $D$. leucomelas because it always occurred under the leaf litter.

During $D$. histrionicus courtships, the male typically approached and called at the female when she approached the male's perch. If the female did not move away, then the male moved away, and 
then stopped and called until the female followed. The male would then move away again. This sequence was repeated until the male went under the leaf litter and called, and the female followed. Oviposition would then occur under the litter. Few tactile interactions were observed during these sequences, although males were occasionally observed to stroke, climb, or jump on the female when the female ignored or rejected the male. In contrast to D. leucomelas, $D$. histrionicus pairs did not engage in extensive leaf litter exploration. Oviposition was observed on one occasion in $D$. histrionicus, when a pair mated under an overhanging leaf that allowed enough light to observe the interaction. After moving onto the leaf on which oviposition occurred, both the female and the male performed several types of movements on the leaf. These movements consisted mostly of crouching down on the leaf and rotating in place (both clockwise and anticlockwise), and rapid kicking movements of the hind legs. Head bobbing and foreleg patting also occurred. In addition, the male repeatedly stroked the female with his foreleg during these movements. When the female began laying eggs, the male climbed on top of her back briefly, and then climbed off and left. The female continued to sit on the eggs and rotate, for approximately $30 \mathrm{~min}$.

Courtship averaged at least $246 \pm 20 \mathrm{~min}$ in $D$. leucomelas $(N=8)$ and $71 \pm 7 \mathrm{~min}$ in $D$. histrionicus $(N=9)$. These are minimum estimates because some courtships had already begun when the pair was observed. During courtship, female $D$. leucomelas were more active in tactile stimulation (i.e. the number of times the female stroked, nudged, climbed on or jumped on the male, and vice versa) than males (Wilcoxon signed-ranks test, $N=22, P=0.001$ ). In contrast, $D$. histrionicus females were not observed to stroke, nudge, climb on, or jump on males.

\section{Selectivity}

The most accurate measures of mate selectivity available for dendrobatids are the results of male-female encounters (Summers 1989). Females rejected or ignored males 30 times in D. leucomelas, and 28 times in D. histrionicus, but males did not reject or ignore females in either species (Fig. 8; chi-squared test; D. leucomelas: 30 versus 0 , $\chi^{2}=20, d f=1, P<0.001 ; D$. histrionicus: 28 versus $\left.0, \chi^{2}=18, d f=1, P<0.001\right)$.

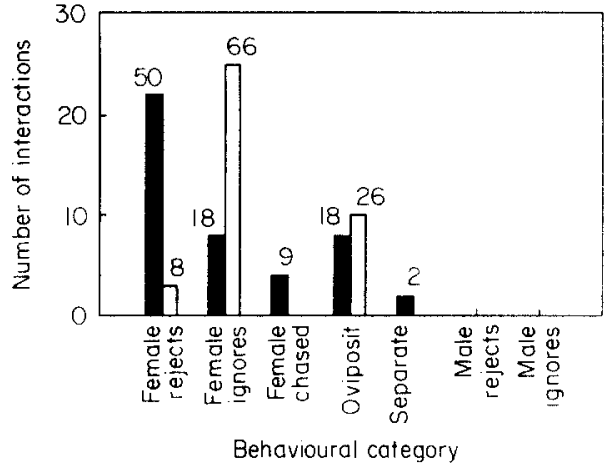

Figure 8. The results of encounter terminations observed in D. leucomelas ( $\square$ ) and D. histrionicus $(\square)$. The number over each bar indicates the percentage of the total number of observations (for each species) that the bar represents. Behavioural categories are described in the Methods section.

\section{Female-Male Associations}

Some female $D$. leucomelas were frequently associated with particular males (Table II). A female would repeatedly court the same male, even though she did not mate with him in that interaction. Two females (females 5 and 6), on separate occasions, actively courted a male that they had fought over, and then rejected him 10-20 min after the other female had left. One of these females was observed mating with the male she had fought for previously (over 3 weeks before). In contrast, no D. histrionicus females were seen to associate with the same male twice, and females were never observed to actively court males. Observations on both species were made during the rainy season, during similar times of day, and mating was observed with equal frequency in both species. Hence, the differences in female-male association patterns between the two species are unlikely to be due to differences in environmental conditions.

\section{Parental Care}

Several male $D$. leucomelas were observed carrying tadpoles to treeholes on the study site. Female $D$. histrionicus were observed carrying tadpoles on several occasions, but tadpole deposition was witnessed only once. The female deposited a single tadpole (out of three on her back) in a stem axil of a Heliconia plant. Another female was observed extruding an egg into the stem axil of a 
Table II. Female-male associations in D. leucomelas

\begin{tabular}{cclll}
\hline Female no. & Observations & Time span & Interactions & Aggression \\
\hline 6 & $2 / 3$ & 2 weeks & 2 rejections & Yes \\
9 & $4 / 5$ & 2 months & $\begin{array}{l}3 \text { rejections } \\
\text { I mating }\end{array}$ & \\
2 & $7 / 8$ & 6 weeks & $\begin{array}{l}5 \text { rejections } \\
2 \text { matings } \\
2 \text { rejections }\end{array}$ & Yes \\
& & & 1 mating & \\
5 & $3 / 3$ & weeks & rejections & \\
4 & $6 / 7$ & 5 weeks & separate & \\
7 & $4 / 4$ & 10 days & rejections & \\
\hline
\end{tabular}

See Methods section for category descriptions.

Calathea plant. Further investigation revealed $D$. histrionicus tadpoles in the stem axils of both of these types of plant on the study site.

\section{DISCUSSION}

\section{Aggression}

Dendrobates histrionicus males did not call more frequently or respond to calls more aggressively than $D$. leucomelas males. This suggests that males were not defending their territories more aggressively, or trying to attract females more vigorously in D. histrionicus. Dendrobates leucomelas engaged in physical aggression more frequently than $D$. histrionicus. These results do not support the sex role reversal hypothesis, but are consistent with the parental quality hypothesis.

Dendrobates leucomelas males generally had larger home ranges than $D$. histrionicus males. Wells (1978) suggested that male D. auratus might keep clutches from different females widely separated to prevent their mates from finding and destroying the clutches of other mates. The differences between species in home range size are consistent with this possibility, although the home ranges of $D$. leucomelas males were quite variable in size. The average and median distance between the centres of home ranges was higher for $D$. histrionicus males, but the larger sample size and the patchy distribution of $D$. histrionicus males on the study site meant that more $D$. histrionicus males were found within $5 \mathrm{~m}$ of their neighbour's home range centre. The home range centre of eight $D$. histrionicus males were within $5 \mathrm{~m}$ of their nearest neighbour; whereas all $D$. leucomelas male home range centres were further than $5 \mathrm{~m}$ apart. There was slight overlap between the home ranges of two pairs of $D$. histrionicus males, but there was no overlap between the home ranges of $D$. leucomelas males.

Zimmermann \& Zimmermann (1980) reported that captive $D$. leucomelas males were not aggressive or territorial in terraria, while females were aggressive. The results reported here show that the behaviour of $D$. leucomelas males in the field was quite different from that in captivity. Observations of male site specificity, response to calls and aggression against intruders, suggest that males are territorial in the wild. As in D. auratus, observations on aggressive intra-sexual interactions do not support the sex role reversal hypothesis, which predicts that female-female aggression will be more common and intense than male-male aggression. Female D. histrionicus were not observed to compete for mates, as predicted by both hypotheses.

\section{Courtship}

Courtship in D. leucomelas in the field was similar to that of captive animals, as described by Zimmermann \& Zimmermann (1980). Courtship in D. histrionicus was similar to that described by Silverstone (1973) in the field, and to descriptions of courtship in captive animals (Zimmermann \& Zimmermann 1981). Silverstone described nine 
different components of courtship; calling, pursuing, touching, sitting, hugging, shaking (hind and forelimb), bowing, crouching and circling. With the exception of hugging, all these behaviour patterns were observed in this study. However, touching was done only by males, and males appeared to lead females to the oviposition site, rather than the reverse. Zimmermann \& Zimmermann (1981) reported that males stroked females, but not the reverse. In contrast, $D$. leucomelas females appeared to take a more active role in courtship.

\section{Selectivity}

Patterns of courtship behaviour and encounter terminations in D. leucomelas were similar to those seen in D. auratus (Wells 1978; Summers 1989). Females actively courted males, but also rejected or ignored males frequently, whereas males did not reject or ignore females. Hence, the active tactile courtship of males by females did not indicate that D. auratus (Summers 1989) or D. leucomelas males were more selective than females about mating. In contrast, females of both species were more selective than males about mating, as predicted by the parental quality hypothesis. Dendrobates leucomelas males were no more selective than their counterparts in $D$. histrionicus, as indicated by the lack of rejection of females by males in both species.

\section{Mate Guarding}

In $D$. auratus some females guard their mates by remaining in or near their mates' territories, courting them frequently, and attacking any other females they encounter courting them (Summers 1989). My observation of a female $D$. leucomelas driving away another female, then courting the male for a while, and then rejecting him, suggest that females may court males actively in order to prevent them from courting and mating with other females. The duration of some female-male associations suggests that some females will guard a particular male over a long period of time. These results are consistent with the prediction of mate guarding derived from the parental quality hypothesis. In contrast, female $D$. histrionicus did not actively court males, and were not observed repeatedly with the same male. In his study on $D$. histrionicus in Colombia, Silverstone (1973) noted that 3 out of 51 females captured near a male (on the same or a neighbouring plant) were recaptured near that male again after periods of 2-11 days. $\mathrm{He}$ did not report any interactions between these individuals. A female was never seen near the same male more than twice. Silverstone concluded that the associations he saw did not support his hypothesis that female and male $D$. histrionicus formed pair bonds to enhance the effectiveness of parental care. Silverstone also noted that females sometimes courted males by stroking them, but did not record the frequency of this tactile stimulation by females. In the two courtships which he described in detail, only the male courted tactually.

\section{Parental Care}

Although observations on parental care in $D$. leucomelas were sparse, the patterns observed were similar to those seen in D. auratus (Summers 1989. 1990b); males apparently deposit tadpoles in small pools of water in treeholes. Silverstone (1973) recorded $D$. histrionicus tadpoles from bromeliad leaf axils, but the use of Heliconia and Calathea stems for deposition of tadpoles had not been recorded previously in this species.

\section{Sexual Selection in Dendrobates}

The comparisons between $D$. leucomelas and $D$. histrionicus support the parental quality hypothesis, and do not support the sex role reversal hypothesis as an explanation of female-female competition for mates in species of Dendrobates with male parental care. Female-female aggression in D. leucomelas appears to be part of a mate guarding strategy that some females employ to prevent their mates from caring for the offspring of other females. The similarities between $D$. leucomelas and D. auratus males and females in mating, aggressive and associative behaviour supports the hypothesis that the potentially variable quality of male parental care in Dendrobates in general has led to the evolution of mate guarding strategies by females in this genus. Because $D$. leucomelas and $D$. auratus probably share a common ancestor more recently than either do with $D$. histrionicus or any other species with female parental care (C. Myers. personal communication), the association of malc parental care with mate guarding by females is likely to be homologous rather than convergent. Hence, the comparison between $D$. leucomelas and $D$. auratus provides support for the hypothesis of a causal relationship between male parental care 
and female aggression, but does not provide the strong evidence that would be provided by the independent evolution of the association in separate lineages (Brooks \& McLennan 1991). Femalefemale competition for mates in association with a conflict of interest between males and females has not been documented in any other genus of frog, but has been indicated in other taxa, particularly redwinged blackbirds (Yasukawa \& Searcy 1982) and pied flycatchers (Breiehagen \& Slagsvold 1988).

\section{ACKNOWLEDGMENTS}

I am deeply indebted to Arnold Kluge, Richard Alexander, A. Stanley Rand, Nancy Knowlton, Richard Wrangham and Brian Hazlett for discussion, advice, criticism and support. I thank Michael Barry for excellent assistance in the field; $\mathrm{Dr}$ Fausto Sarmiento R., Dr Sergio Figuerroa S., the Ecuadorean National Museum of Natural Sciences and the Ecuadorean Ministry of Agriculture and Livestock for assistance with logistics and permits in Ecuador; Stefan Gorzula for friendship, logistical support, and for letting me stay in his house for three months; Luis Balbas and Asterio Farrera for support and guidance in the field; EDELCA for permission to work at Guri, Venezuela; Charles Myers for advice and for data. This project was supported by funding from the Smithsonian Institution, the Smithsonian Tropical Research Institute, the Sigma Xi Scientific Society, the Explorers Club, the Horace H. Rackham School of Graduate Studies, the Museum of Zoology and the Department of Biological Sciences, University of Michigan.

\section{REFERENCES}

Berglund, A., Rosenqvist, G. \& Svensson, I. 1986a. Mate choice, fecundity and sexual dimorphism in two pipefish species (Syngnathidae). Behav. Ecol. Sociobiol., 19, 301-307.

Berglund, A., Rosenqvist, G. \& Svensson, I. 1986b. Reversed sex roles and parental energy investment in zygotes of two pipefish (Syngnathidae) species. Mar. Ecol. Progr. Ser., 29, 209-215.

Blaffer Hrdy, S. \& Williams, G. C. 1983. Behavioral biology and the double standard. In: Social Behavior of Female Vertebrates (Ed. by S. K. Wasser), pp. 3-17. New York: Academic Press.

Breiehagen, T. \& Slagsvold, T. 1988. Male polyterritoriality and female-female aggression in pied flycatchers Ficedula hypoleuca. Anim. Behav., 36, 604-605.
Brooks, D. R. \& McLennan, D. A. 1991. Phylogeny. Ecology and Behavior. Chicago: University of Chicago Press.

Bunnell, P. 1973. Vocalizations in the territorial behavior of the frog, Dendrobates pumilio. Copeia, 1973, 277-284.

Crump, M. L. 1972. Territoriality and mating behavior in Dendrobates granuliferus (Anura: dendrobatidae). Herpetologica, 28, 195-198.

Gwynne, D. J. 1981. Sexual difference theory: mormon crickets show role reversal in mate choice. Science, 213, $779-780$.

Jenni, D. A. \& Collier, G. 1972. Polyandry in the American jacana (Jacana spinosa). Auk, 89, 743-765.

McVey, M. E., Zahary, R. G., Perry, D. \& Dougal, J. M. 1981. Territoriality and homing behavior in the poison dart frog (Dendrobates pumilio). Copeia, 1981, I-8.

Myers, C. W. \& Daly, J. W. 1976. Preliminary evaluation of skin toxins and vocalizations in taxonomic and evolutionary studies of poison-dart frogs (Dendrobatidae). Am. Mus. Novit., NY., 157, 173-262.

Myers, C. W. \& Daly, J. W. 1983. Dart-poison frogs. Sci. Am., 248, 120-133.

Oring, L. W. \& Maxson, S. J. 1978. Instances of simultaneous polyandry by a spotted sandpiper, Actitis macularia. Ibis, 120, 349-353.

Rosenquist, G. 1990. Male mate choice and female female competition for mates in the pipefish Nerophis ophidion. Anim. Behav., 39, 1110-1115.

Salthe, S. N. \& Mecham, J. S. 1974. Reproductive and courtship patterns. In: Physiology of the Amphibia. Vol. III (Ed. by B. Lofts), pp. 309 521. New York: Academic Press.

Senftt, W. 1936. Das Brutgeschaft des Baumsteigerfrosches (Dendrobates auratus Girard). Gefangenschaft. Zool. Garten., 8, 122-136.

Silverstone, P. A. 1973. Observations on the behavior and ecology of a Colombian poison-arrow frog, the Kokoepa (Dendrobates histrionicus Berthold). Herpetologica, 29, 295-301.

Silverstone, P. A. 1975. A revision of the poison-arrow frogs of the genus Dendrobates Wagler. L. A. Nat. Hist. Mus. Sci. Bull., 21, 1-55.

Smith, R. L. 1979. Paternity assurance and altered roles in the mating behaviour of a giant water bug, Abedus herberti (Heteroptera: Belostomatidae). Anim. Behav., 27, 716-725.

Summers, K. 1989. Sexual selection and intra-female competition in the green dart-poison frog, Dendrobates auratus. Anim. Behav., 37, 797-805.

Summers, K. 1990a. Parental investment and sexual selection in dart-posion frogs (Dendrobatidae). Ph.D. thesis, University of Michigan, Ann Arbor.

Summers, K. 1990b. Parental care and the cost of polygyny in the green dart-poison frog, Dendrobates auratus. Behav. Ecol. Sociobiol., 27, 307-313.

Trivers, R. L. 1972. Parental investment and sexual selection. In: Sexual Selection and the Descent of Man 1871-197/ (Ed. by B. Campbell), pp. 136-179. Chicago: Aldine-Atherton.

Wells, K. D. 1977. The courtship of frogs. In: The Reproductive Biology of Amphibians (Ed. by D. $\mathbf{H}$. Taylor \& S. I. Guttman), pp. 233-262. New York: Plenum Press. 
Wells, K. D. 1978. Courtship and parental behavior in a Panamanian poison-arrow frog, (Dendrobates auratus). Herpetologica, 34, 148-155.

Wells, K. D. 1981. Parental behavior of male and female frogs. In: Natural Selection and Social Behavior (Ed. by R. D. Alexander \& D. W. Tinkle), pp. 184-197. New York: Chiron Press.

Weygoldt, P. 1980. Complex brood care and reproductive behaviour in captive poison-arrow frogs, Dendrobates pumilio O. Schmidt. Behav. Ecol. Sociobiol, 7, 329-332.

Weygoldt, P. 1987. Evolution of parental care in dartpoison frogs (Amphibia: Dendrobatidae). Z. Zool. Syst. Evolut.-forsch., 25, 51-67.

Williams, G. C. 1966. Adaptation and Natural Selection. Princeton: University of Princeton Press.

Wilkinson, L. 1987. SYSTAT: the System for Statistics. Evanston, Illinois: Systat.

Wittenberger, J. F. 1979. The evolution of mating systems in birds and mammals. In: Handbook of Behavioral Neurobiology. Vol. 3: Social Behavior and
Communication (Ed. by P. Marler \& J. G. Vandenburg), pp. 271-349. New York: Plenum Press.

Yasukawa, K. \& Searcy, W. A. 1982. Aggression in female red-winged blackbirds: a strategy to ensure male parental investment. Behav. Ecol. Sociobiol., 11, 13-17.

Zimmermann, H. \& Zimmermann, E. 1980. Durch Nachzucht erhalten: der Baumsteiger Dendrobates leucomelas. Aquarien. Mag., 14, 211-217.

Zimmermann, H. \& Zimmermann, E. 1981. Sozialverhalten, Fortpflanzngsverhalten und Zucht der Farberfrosche Dendrobates histrionicus und D. lehmanni sowie einiger anderer Dendrobatiden. Z. Kolner Zoo., 24, 83-99.

Zimmermann, E. \& Zimmermann, H. 1982. Soziale Aktionen, Brutpflege und Zucht des Pfeilgiftfrosches Dendrobates histrionicus. Salamandra, 18, 150-167.

Zimmermann, H. \& Zimmermann, E. 1988. Ethotaxonomie und Zoographische Artenggruppenbildung bei Pfeilgiftfroschen (Anura: Dendrobatidae). Salamandra. $24,125-160$. 